\title{
Use of canopy gap openings to restore coniferous stands in Mediterranean environment
}

\author{
Adele Muscolo, \\ Giovanna Settineri, \\ Silvio Bagnato, \\ Roberto Mercurio, \\ Maria Sidari
}

\begin{abstract}
In Mediterranean regions, climate change increasingly affect tree species dis tributions. Conifer forests under continuing disturbance show a more rapid shift to dominance by beech and other temperate broadleaves. Thus, there is an urgent need to conserve coniferous vegetation to avoid local extinction. Gap opening has profound effects on the structure and dynamics of most forests and may represent a sustainable way to restore coniferous ecosystems in Mediterranean habitats. What kind of artificial canopy opening is the most sustainable and effective means for restoring coniferous ecosystem functions? We explored the efficacy of artificial gaps in regeneration and dynamics of coniferous in Mediterranean environment. We examined how regeneration of different tree species is associated with soil environmental conditions and how gaps of different sizes influence the ecology and management of Mediterranean forest. Specifically, we analyzed gap disturbance in silver fir and black pine stands, as they dominate central and southern Italian forests. We demonstrated a specificity between gap size and coniferous species regeneration, indicating that small gaps (about $200 \mathrm{~m}^{2}$ ) favor silver fir regeneration, while black pine, depending on its subspecies, regenerates both in small and medium gaps (about $500 \mathrm{~m}^{2}$ ). Further, we found that gap characteristics (age and shape) and suitable substrate availability are the primary factors affecting seedling establishment. Our results provide functional information to design a silvicultural system useful to manage the natural regeneration of Mediterranean forest minimizing the environmental and visual impact.
\end{abstract}

Keywords: Biodiversity, Gap Cutting, Gap Dynamic, Forest Conservation, Forest Restoration

\section{Introduction \\ Mediterranean ecosystems are highly sensitive to climate change, as relatively minor decreases in rainfall and increases in temperature may lead to the expansion of adjacent semi-arid and arid ecosystems at the expense of Mediterranean ecosystems. Mediterranean ecosystems show changes in their community structure with competi- tive relationships between species leading to tree migration in the long term (Caplat et al. 2008). However, in the short term, the physiological limits of tree growth at the warmer and drier distribution limit are most important as they may determine the local species extirpation (Fang \& Lechow- icz 2006). Conifer forests under continuous}

disturbance show a more rapid shift to dominance by beech and other temperate broadleaves, therefore there is an urgent need to conserve in situ coniferous species (Lindner et al. 2010).

Gap cutting is a silvicultural tool that consists of removing all trees in very small areas, i.e., "punching a hole" at different spatial and temporal scales in a continuous forest cover, to allow the establishment of new regeneration. For Mediterranean forest ecosystems, this silvicultural tool represents the most sustainable form of management from an economic and energetic point of view (Scarascia-Mugnozza et al. 2000). Giacobbe (1958) was the first Italian silviculturist who evidenced the important

Department of Agriculture, “Mediterranea” University, Loc. Feo di Vito, I-89122 Reggio Calabria (Italy)

@ Adele Muscolo (amuscolo@unirc.it)

Received: Jan 13, 2016 - Accepted: Sep 17, 2016

Citation: Muscolo A, Settineri G, Bagnato S, Mercurio R, Sidari M (2017). Use of canopy gap openings to restore coniferous stands in Mediterranean environment. iForest 10: 322-327. doi: 10.3832/ifor1983-009 [online 2017-02-23]

Communicated by: Andrea Cutini ecological role of gaps in Mediterranean forests, with remarkable consequences both for natural regeneration and wood production. In the international literature, Coates \& Burton (1997) first proposed the concept of "gap-based approach" "to develop novel silvicultural systems for improving or maintaining timber production without compromising ecosystem functioning". Van der Meer et al. (1999) used for the first time the term "gap-cutting system"; subsequently, different terms have been used in the literature, such as:

- group selection method (removing mature trees in small group or clusters - Nyland 2002);

- patch-selection method (add some patch equal to the height of a mature tree within single-tree selection method - Nyland 2002);

- group selection system $\left(100-1000 \mathrm{~m}^{2}\right.$, Smith et al. 1997; 400-1000 m², Seymour et al. 2002);

- irregular shelter wood (100-1000 $\mathrm{m}^{2}$ Smith et al. 1997);

- small patch cuts (1000-5000 $\mathrm{m}^{2}$ - Coates \& Burton 1997).

The successful regeneration of tree species in gaps depends not only on the gap size but also on many other variables such as: age of seed trees, proximity of seed source to gaps, mechanism of seed disper- 
sal, substrate conditions, plant-herbivore relationship, number (density) of gaps, spatial and temporal gap distribution (Ren et al. 2015). Other more subtle characteristics of canopy gaps influencing post-gap regeneration are the shape and exposure (Sapkota et al. 2009), that affect PAR availability inside the gap (Dahir \& Lorimer 1996); height and diameter of the surrounding trees (Denslow 1980); gap age (Barik et al. 1992, Schnitzer \& Carson 2001); number, cause and size of tree fall (Xi et al. 2008); gap canopy height (Barik et al. 1992) and surrounding stand structure (Gagnon et al. 2004). Canopy gap opening has been used for ecological restoration (Hamer et al. 2003), and gap dynamics has been described in many forests, such as temperate evergreen broadleaf (Rebertus \& Veblen 1993, Yamamoto 1994), temperate deciduous broadleaf (Runkle 2000), temperate conifer (Spies et al. 1990), subalpine (Lertzman 1992, Yamamoto 1995) and boreal forests (Kneeshaw \& Bergeron 1998). Although many researches on gap dynamics have been conducted in old-growth forests, application of gap dynamic to forest practice is still scarce. However, the accumulated knowledge on gap dynamics could be useful for sustainable forest ecosystem management, as much of the literature suggests.

Generally, forest restoration management can be broken down into three approaches, each with different aims relating to different functions of the forests to be restored.

1. Forest restoration is used to rehabilitate a functional ecosystem without emphasizing production functions. The strategy is the restoration of the previously stable production potential. This case of restoration management is not limited to protected areas.

2. Conversion to a near-natural forest, leaving the forest to spontaneous development. This is always applicable to forests in protected areas. Nonetheless, this approach is the least applied among the three considered. A special variant of this approach is "zero management", i.e., the spontaneous regeneration of forest where strong disturbances have taken place either in large areas or affecting basic forest functions. The ecosystem is in its initial development phase, but its restoration is left to the spontaneous effects of natural factors.

3. Restoration of forests to a certain state (even if conditioned by man) requires long-term, active management to allow to the endangered species to survive. This approach is currently mostly applied to forests in protected areas and has the protection of biological diversity as priority (Vrška et al. 2006).

The rehabilitation of conifer monocultures in stands with high diversity in composition and structure represents one of the main objectives of silviculture, to suggest management practices useful to meet the sustainable development. Therefore, a deeper knowledge on gap dynamics is fundamental to predict species composition and successional dynamic, and optimize silvicultural strategies for the sustainable management of coniferous forests (Burton \& Macdonald 2011).

The goal of this review is to summarize new and previously published data to provide a coherent picture of the role of treefall gaps in coniferous forest regeneration and dynamics. Our aim was to determine the degree to which there is empirical support for the gap hypothesis, defined as the variety of ideas on the role of gaps in the maintenance of diversity (Schnitzer et al. 2008). We restricted our definition of the gap hypothesis to canopy gaps that are formed by cutting trees in the forest. Specifically, we examined gap disturbance in silver fir, black pine and Calabrian pine stands, as they occurs in the majority of Mediterranean forests. The aim is to provide knowledge on the capacity of gapbased silvicultural regimes to change and/ or enrich tree species composition, leading to more complex structures that create different habitats for fauna and flora, thus driving forest biodiversity conservation. The specific insight may be useful to nature conservation authorities and forestry organizations to manage the natural regeneration of forest trees with very low environmental and visual impact. Because of the many variables involved, there is no standard definitions of gap size. It may be defined by the relative height of the surrounding canopy or by the amount of direct sunlight reaching the gap (York et al. 2003). Gap area is usually measured between the drip lines of the surrounding trees, but an extended gap also includes the area between tree stems (Runkle 1982). Likewise, the definition of gap area is difficult, and can vary by a factor of 2 depending on how it is measured (Brokaw 1985). In many gap studies, a large gap is defined for convenience as greater than $1000 \mathrm{~m}^{2}$ (Schliemann \& Bockheim 2011). In New Zealand beech forests, Stewart et al. (1991) considered a gap to be anything larger than $20 \mathrm{~m}^{2}$. In studies of gaps or groups created through silvicultural interventions, sizes up to 1 ha are common. Bradshaw (1992) speculated that, based on the traditional silvicultural definition of gap as anything influenced by edges (Daniel et al. 1979), in a forest with very tall trees a gap could be 10 ha in size. This range in gap/group size, by itself, creates a huge variability in the post disturbance response. We grouped the gaps in size as follows: (i) small gaps: no larger than $250 \mathrm{~m}^{2}$; (ii) medium gaps; from 250 to approximately $860 \mathrm{~m}^{2}$; and (iii) large gaps, greater than $860 \mathrm{~m}^{2}$. This classification was arbitrarily chosen for a better understanding of the results.

\section{Methods}

This review is based on the results of a lit- erature survey which focused on papers published in the period 1958-2015 using as keywords (either alone or in combination): "gap size", "gap age", "gap shape" and "coniferous regeneration". The majority of the articles included in this review were published in international peer review journals written in English and included at least one field experiment using gap creation for restoration or reforestation purpose. We found 110 papers that matched these criteria. We classified the selected papers according to the kind of gap, and the vegetation type. The experiments were divided according to the species and gap size. We summarized survival and mortality as well regeneration success of the silver fire, black pine and Calabrian pine in respect to the gap size and age.

\section{Results and discussion}

\section{Silver fir stands}

It is well known that resources such as solar radiation, soil moisture, and soil nutrients, strongly vary from the edge to the interior of gaps, thus influencing species with different regeneration requirements. Based on this assumption, the first Italian experience with the use of gap cutting for the rehabilitation of conifer monoculture began in 1982, in a 80-100 years-old silver fir (Abies alba Mill.) plantation, located in the Casentinesi forest $\left(43^{\circ} 47^{\prime} \mathrm{N}, 11^{\circ} 49^{\prime} \mathrm{E}\right)$, central Apennines (Mercurio 2000, Cutini et al. 2004). Following gap opening, shade intolerant species were replaced by shadetolerant ones (Mercurio \& Spampinato 2001), showing that broadleaved trees successfully regenerated in gap centers, while silver fir regenerated in the gap edges (Mercurio 2000, Cutini et al. 2004). It was also demonstrated that the regeneration of both species was much better in gaps of $540 \mathrm{~m}^{2}$ than in gaps of $874 \mathrm{~m}^{2}$. Gap size of $540 \mathrm{~m}^{2}$ was sufficiently large to supply resource and allow species to stably coexist at equilibrium. The main species present in the forest, such as mountain maple (Acer pseudoplatanus L.), beech (Fagus sylvatica L.), rowan (Sorbus aucuparia L.) and silver fir, regenerated better inside the 540 $\mathrm{m}^{2}$ gaps than in the larger one. The secondary species white beam (Sorbus aria L. Crantz.), laburnum (Laburnum anagyroides Medik.) and willow (Salix caprea L.) also regenerated well inside the smaller gaps. In the $540 \mathrm{~m}^{2}$ gaps tree species diversity was high (7 species or more per gap on average, similar to tree species diversity measured in the neighboring stands), while in the gaps of $874 \mathrm{~m}^{2}$ tree species diversity and natural regeneration were lower. Mercurio (unpublished data) started in 1999 a new trial of experiments in the same area of the same forests, opening gaps of smaller size than $540 \mathrm{~m}^{2}$ (379 and $215 \mathrm{~m}^{2}$ ). The results obtained 11 years after gap opening showed that silver fir seedling density was higher in $379 \mathrm{~m}^{2}$ than in $215 \mathrm{~m}^{2}$ gaps (unpublished data). 
Tab. 1 - Structural dynamics and natural regeneration of different silver fir stands in Central and Southern Italy. (*): including one years old seedlings; (a) tree species are ordered by decreasing frequency.

\begin{tabular}{|c|c|c|c|c|c|c|c|c|c|c|}
\hline Location & $\begin{array}{l}\text { Forest } \\
\text { type }\end{array}$ & 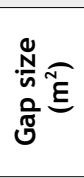 & $\frac{5}{\partial}$ & 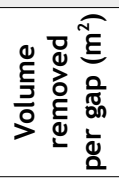 & 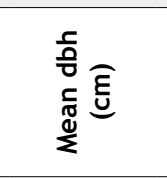 & 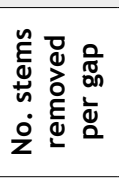 & 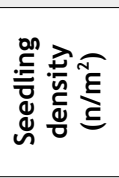 & 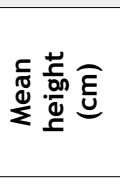 & 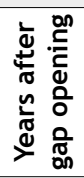 & Tree species $^{a}$ \\
\hline \multirow[t]{3}{*}{$\begin{array}{l}\text { Serra San Bruno } \\
\text { (unpub. data) }\end{array}$} & Silver fir & 410 & $1: 0.75$ & 25.0 & $\begin{array}{c}47.6 \\
\text { (stem base) }\end{array}$ & 19 & 4.6 & 21.8 & 10 & silver fir, chestnut \\
\hline & Silver fir & 185 & $1: 0.5$ & 9.9 & $\begin{array}{c}40.1 \\
\text { (stem base) }\end{array}$ & 8 & 8.4 & 17.1 & 10 & silver fir, chestnut \\
\hline & Silver fir & 872 & $1: 1$ & 62.9 & 35.6 & 46 & 0.4 & 51.9 & 18 & silver fir, maple, beech \\
\hline \multirow[t]{2}{*}{ Foreste Casentinesi } & Silver fir & 540 & $1: 1$ & 27.8 & 32.4 & 35 & 1.3 & 22.6 & 18 & $\begin{array}{l}\text { maple, silver fir, beech, } \\
\text { rowan }\end{array}$ \\
\hline & Silver fir & 379 & $1: 0.75$ & 13.9 & 39.4 & 6.2 & $5.4^{*}$ & 10.1 & 11 & silver fir \\
\hline $\begin{array}{l}\text { Foreste Casentinesi } \\
\text { (unpub. data) }\end{array}$ & Silver fir & 215 & $1: 0.5$ & 39.6 & 39.6 & 15 & $4.9^{*}$ & 9.5 & 11 & silver fir \\
\hline
\end{tabular}

With an experiment started in a 90 yearold silver fir plantation in Serra S. Bruno, located in Southern Apennines $\left(38^{\circ} 33^{\prime} \mathrm{N}\right.$, $16^{\circ} 19^{\prime} \mathrm{E}$ ), Albanesi et al. (2005) evaluated if the creation of gaps was an appropriate method to induce natural regeneration in a homogeneous plantations of silver fir (Abies alba Mill.). They analyzed the influence of micro-environmental conditions in gaps of two sizes, small $\left(185 \mathrm{~m}^{2}\right)$ and medium $\left(410 \mathrm{~m}^{2}\right)$, evaluating the recruitment and establishment of natural regeneration of forest tree species. Their results showed that, after three growing seasons, silver fir seedling recruitment was significant in the central-southern positions within small gaps, where the PAR was low and the shading influence of ground vegetation was less relevant. The most suitable gap size for silver fir regeneration in the southern Apennines was $185 \mathrm{~m}^{2}$, with diameter/ height $=0.5$. The silvicultural treatment fostered natural regeneration of silver fir, enhancing the development of a multi-layered forest structure and fulfilling timber production objectives without compromising ecosystem management principles. Subsequently, in the same experimental area, Muscolo et al. (2007a) investigated the changes in soil chemical and microbiological parameters over 2 years in the same small $\left(185 \mathrm{~m}^{2}\right)$ and medium $\left(410 \mathrm{~m}^{2}\right)$ gaps. Medium gaps had higher soil temperature, PAR transmittance and low soil moisture than small gaps. A greater amount of organic matter was observed within small gaps, as compared to under canopy cover sites and medium gaps. Moreover, a different trend of organic matter between small and medium gaps was observed. In the medium gaps, with respect to under canopy cover sites and small gaps, they found a relatively low content of organic matter, associated to a low amount of humic acids. These results suggested that the organic matter was subject to a mineralization rather than a humification process. An opposite trend was observed in small gaps, where an increase in organic matter content associated to an increase in humic acids and microbial biomass re- flected a better humification process. The different trend in organic matter observed in small and medium gaps has been related to changes in the environmental conditions. PAR transmittance, significantly higher in medium gaps, contributed to increase soil temperature and to decrease soil moisture, affecting soil microbial populations and organic matter trend. The greatest amount of microbial biomass and the largest populations of bacteria and fungi in small gaps contributed to more rapid and balanced turnover of organic matter and nutrients, indicating that the creation of small gaps represents a silvicultural practice with minor environmental impact. The same authors (Muscolo et al. 2010) related changes in soil properties to natural regeneration of silver fir. Their results indicated that within small gaps, there was more silver fir regeneration than in medium gaps. Differences in the amount of phenolic compounds may account for the observed differences in natural regeneration of silver fir between small and medium gaps. Similar results for silver fir regeneration were found by Bottalico et al. (2014) in the Vallombrosa forest (Tuscan Apennines, Italy). Bianchi et al. (2011) studied the regeneration of silver fir and demonstrated that when the gaps were quite large, the regeneration layer reached the top layer and the structure stand tended, once more, toward a single-layer. Multilayered structures were extremely rare at plot level and became evident only at a wider scale. Their surveys also indicated a high variability of tree diameter distribution patterns in the forest stands. Such variability could be strictly related to the heterogeneity of site as well as to the effects of disturbance factors (both natural and anthropic). Concerning altitude, the same authors observed an increase both in site index (dominant height) and species diversity in the regeneration layer, moving from higher $(1500 \mathrm{~m})$ to lower $(900 \mathrm{~m})$ altitudes. Overall, the results showed that the dynamics of forest vegetation were mostly affected by the interruption of tree canopy continuity. This implied substantial local variations of PAR in space and in time, which determined favorable ecological conditions for: (i) survival and growth of beech seedlings, or release of advanced beech regeneration; and (ii) release of advanced silver fir regeneration, as fir is more shade tolerant than beech, and regenerates mainly in locations and conditions where beech saplings could not survive for lacking of light (Madsen 1995). Several studies in other regions of the globe indicated that even larger gap sizes are often dominated by shade-tolerant species when pre-disturbance communities contain high levels of advance regeneration (Madsen \& Hahn 2008). In short, the structural dynamics and the natural regeneration of silver fir are strictly dependent on gap size, volume removed per gap, and gap opening time, showing that the best seedling density was 10 years after gap opening in gaps with small size and with less volume removed (Tab. 1).

The results related to the mechanisms of vegetation dynamics in the Strict Natural Reserve of Sasso Fratino (Central Italy) may be used as basis for close-to-nature silvicultural choices in similar stands in order to increase forest functionality and stability.

\section{Black pine stands}

Black pine (Pinus nigra Arn.) is a circumMediterranean pine species, whose natural range extends from Spain and north Morocco to Austria, Turkey and Cyprus. Most forests occur in mountainous areas between 1000 and $1500 \mathrm{~m}$ a.s.l. As a result, its populations are fragmented and exhibit high morphological, physiological and ecological variability. Pinus nigra proved to be particularly suitable for reforesting slopes with shallow soils and harsh climatic conditions (e.g., prolonged summer drought and intense autumn rainfalls). Black pine was also successfully used in other northern Mediterranean countries (Rey \& Berger 2006, Fernández-Ondoño et al. 2010).

In 2000, a study was started on the effects of 108 and $207 \mathrm{~m}^{2}$ artificial gaps as a restoration method in two Black pine stands of 50 and 90 years old, respectively, 
in Monte Plaia, Central Apennines ( $42^{\circ} 01^{\prime}$ $\left.\mathrm{N}, 13^{\circ} 54^{\prime} \mathrm{E}\right)$. Three and nine years following gap creation, Gugliotta \& Mercurio (2003) and Mercurio et al. (2009) showed that artificial gap opening in Black pine stands allowed the establishment of numerous broadleaf seedlings, transforming the forest into mixed stands. The results of tree species dynamics showed that black pine dominated the regeneration nine years after gap opening, but other broadleaved trees, such as pubescent oak (Quercus pubescens Willd.), holm oak (Quercus ilex L.), hop-hornbeam (Ostrya carpinifolia Scop.) and manna-ash (Fraxinus ornus L.) were present in the gaps. Their results confirmed that the gap-cutting represents an effective instrument for natural regeneration within coniferous plantations, mainly in the gaps of $150-250 \mathrm{~m}^{2}$ (small gaps). Muscolo et al. (2011) confirmed these findings, showing that the best black pine seedling establishment was observed in gaps of 207 $\mathrm{m}^{2}$. This was the result of the combined effects of increased light, with fast litte decomposition rate. Additionally, the different concentration of water soluble phenols found in gaps of different sizes may be the cause of different Black pine regeneration among the gaps. The authors found in the gaps with $\mathrm{d}: \mathrm{h}=1\left(207 \mathrm{~m}^{2}\right)$ a lower amount of phenols compared to the othe sites, and this may be the reason for the major establishment of Black pine seedlings. The high amount of phenols in gaps with $\mathrm{d}: \mathrm{h}=0.75\left(108 \mathrm{~m}^{2}\right)$ can inhibit Pinus seedlings growth or delay germination lim iting the offspring of the species. These results highlighted that the high levels of phenols in the different gaps were partially responsible for the lack of the broadleaf species regeneration. In short, the choice of gap size depends on the species to be regenerated that will become dominant in the gap. Gaps of $\sim 200 \mathrm{~m}^{2}$ seem to be the most effective for increasing the dominance and structural heterogeneity of Black pine. This offers a better opportunity to recreate the evolutionary environment of Black pine forests (Tíscar \& Linares 2011). Black pine exhibits poor shade tolerance and regenerates in small gaps. However, a lack of tree diversity in black pine-dominated forests is observed when $\sim 200 \mathrm{~m}^{2}$ artificial gaps are used.

Calabrian pine (Pinus nigra Arn. ssp. laricio Poiret var. Calabrica Delamare) is en- demic to southern Italy with a natural range extending from Sicily to Calabria. In Sicily it grows in fragmented areas on the slopes of Mount Etna between 1000 and $2000 \mathrm{~m}$ a.s.l., covering approximately 4000 ha. In Calabria this pine covers approximately 57,000 ha (MAF/ISAFA 1988), growing on the Aspromonte Mountain at the southern tip of the region, and on the Sila Plateau, from 900 up to $1600 \mathrm{~m}$ a.s.l. Calabrian pine has also been employed in other Italian regions for the reafforestation of degraded lands, often mixed with Austrian pine (Ciancio et al. 2006). Experiments were launched in 2003 in artificial stands of 50 years-old Calabrian pine in Southern Apennines ( $38^{\circ} 42^{\prime} \mathrm{N}, 16^{\circ} 20^{\prime} \mathrm{E}$ ). Gugliotta et al. (2006) studied the seedlings establishment in $380 \mathrm{~m}^{2}$ (small), 855 $\mathrm{m}^{2}$ (medium) and $1520 \mathrm{~m}^{2}$ (large) gaps artificially created. After three growing seasons the results indicated no significant differences in water soil content between the gap of different sizes, a higher transmittance in large and medium gaps than in the small ones, as well as in the center and north sides of all the gaps. A higher density of Calabria pine seedlings was observed in large gaps compared to medium and small ones, mainly in the gap center. In addition, the authors found a great amount of silver fir seedlings in small and medium gaps after the second growing season. A great seedling mortality of Calabrian pine was found at the edge of small and medium gaps, while a great silver fir seedling mortality was observed in the center of the large ones, suggesting that in these first years the ground vegetation (bramble and bracken) exerted a moderate detrimental effect on seedlings establishment, that could be removed by partial cuttings. After 8 years, pine regeneration dominated inside large gaps, whereas native species such as silver fir and beech prevailed inside small gaps. Subsequently, Muscolo et al. (2007b), in the same experimental area, examined the impacts of small $\left(380 \mathrm{~m}^{2}\right)$, medium $\left(855 \mathrm{~m}^{2}\right)$ and large $\left(1520 \mathrm{~m}^{2}\right)$ gaps on microclimate, soil properties and microbial biomass acting as a "source" of plants nutrients. Their results indicated that PAR transmittance significantly increased with increasing gap sizes, with important consequences on the local microclimate. Soil moisture and temperature were different among the gaps of different sizes, with the highest values of temperature in the large gaps and the highest values of moisture in the small gaps. Within small gaps the greatest amount of organic matter, humic matter, microbial biomass and the highest $\mathrm{C} / \mathrm{N}$, phosphatases, urease and FDA values were also observed. An impact of gap size on $C$, $\mathrm{N}$ and $\mathrm{P}$ cycles was significant in small gaps in terms of higher availability of these nutrients and greater amount of humic matter. This suggests that small gaps may be important from an ecosystem perspective, as they preserve soil properties and favor Pinus nigra natural regeneration. Therefore, the creation of small gaps represents an appropriate management procedure for the conservation of ecological functions in these ecosystems. Structural dynamics and natural regeneration of Calabrian pine in different forest stands are shown in Tab. 2.

In summary, the irregular shelterwood system adopted in all these experimental sites showed a clear pattern of gap partitioning among tree species: shade-tolerant and intermediate shade-intolerant species achieved the highest probability of presence in the vicinity of gap edges. On the contrary, shade-intolerant wind-dispersed species achieved the highest probability of presence at the gap center. Small gaps are able to mimic the natural successional pattern that eventually can restore the latesuccessional condition of species. Trees in the border of gaps tend to have a higher rate of disturbance. While opening a gap in a dense forest may result in wind damage, such risk can be avoided or minimized by properly designed gap-cutting. Forest dynamics is also related to the temporal scale, that is an important factor in determining the modification of forest structure and plant species composition across forest succession. Boyden et al. (2005) and Chumanová-Vávrová et al. (2015) studied the relationship between the temporal pattern of change and the dynamics of forest regeneration, highlighting the importance of a series of natural disturbances, such as tree mortality resulting from self-thinning. Our experimental data showed that the rehabilitation of artificial conifer stands in Italy has to be carried on for a total regeneration cycle of about 30 years by adopting the following management technique: first gap cutting, concerning at about $25 \%$ of the total forest surface, has to be adapted to the distribution and shape of the gaps and

Tab. 2 - Structural dynamics and natural regeneration of different Calabrian pine stands in Southern Italy. (*): including one years old seedlings; (a) tree species are ordered by decreasing frequency.

\begin{tabular}{|c|c|c|c|c|c|c|c|c|c|c|}
\hline Location & Forest type & 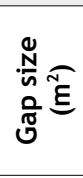 & ริ & 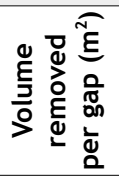 & 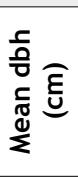 & 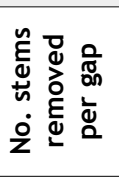 & 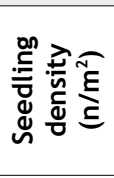 & 兽 & 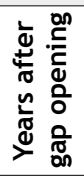 & Tree species ${ }^{a}$ \\
\hline \multirow[t]{3}{*}{ Bufalaria } & Calabrian pine & 1520 & $1: 2$ & 70.3 & 32.2 & 78 & $2.3^{*}$ & 65.9 & 8 & pine, silver fir \\
\hline & Calabrian pine & 855 & $1: 1.5$ & 40.3 & 34.6 & 43 & $2.1^{*}$ & 46.6 & 8 & pine, silver fir \\
\hline & Calabrian pine & 380 & $1: 1$ & 15.1 & 32.1 & 20 & $0.3^{*}$ & 40.2 & 8 & silver fir, pine \\
\hline
\end{tabular}


Tab. 3 - Gap cutting applied in the rehabilitation of man-made conifer stands in Italy.

\begin{tabular}{|c|c|c|c|c|c|c|}
\hline Forest types & Location & $\begin{array}{l}\text { Stand Age } \\
\text { (years) }\end{array}$ & $\begin{array}{c}\text { Gap size } \\
\left(\mathrm{m}^{2}\right)\end{array}$ & $\begin{array}{l}\text { Stand surface } \\
\text { removed (\%) }\end{array}$ & $\begin{array}{c}\text { Interval } \\
\text { (years) }\end{array}$ & Notes \\
\hline Silver fir & $\begin{array}{l}\text { Southern } \\
\text { Apennines }\end{array}$ & $79-80$ & $200-400$ & 25 & 10 & $\begin{array}{l}\text { Vegetation control, cleanings and thinning of } \\
\text { regeneration }\end{array}$ \\
\hline Silver fir & $\begin{array}{l}\text { Central } \\
\text { Apennines }\end{array}$ & $70-80$ & $500-600$ & 25 & 10 & Cleanings and thinning of regeneration \\
\hline Black pine & $\begin{array}{l}\text { Central } \\
\text { Apennines }\end{array}$ & $60-70$ & $150-250$ & 25 & 10 & Larger gaps maintain an higher presence of pine \\
\hline Calabrian pine & $\begin{array}{l}\text { Southern } \\
\text { Apennines }\end{array}$ & $60-70$ & $400-1500$ & 25 & 10 & Larger gaps maintain an higher presence of pine \\
\hline
\end{tabular}

to the site conditions. A further $25 \%$ of the standing forest has to be opened after 10 years, taking care that the new gaps are not adjacent to those opened earlier. The rest of the forest has to be harvested after further 10 years (Tab. 3 ). In addition, when small artificial gaps are used no diversity of trees in young pine-dominated forests was observed. However, even small gaps can be effective in creating size and age variation of the dominant species, increasing the structural heterogeneity of the stands.

\section{Conclusions}

Gaps created by irregular shelterwood system play an important role in forest ecology, helping to preserve bio- and pedodiversity, influencing nutrient cycles, maintaining the complex structure of the latesuccessional forests, and minimizing the adverse impacts on complex ecological processes that shape together the forest landscape.

The size of gaps dramatically affects light intensity and consequently air and soil temperature, soil moisture and soil biological properties, which in turn influence tree species regeneration. Our results revealed that the availability of suitable substrates is the primary factor that limits seedling recruitment following gap logging. This review indicates a clear relationship between gap size and coniferous species regeneration in the Mediterranean environment, highlighting that small gaps (about $200 \mathrm{~m}^{2}$ ) favor silver fir and black pine regeneration, while large gaps (approximately $500 \mathrm{~m}^{2}$ ) promote Calabrian pine restoration. We reported the necessary information to design a management system that mimics the natural disturbance regime, favoring the restoration and conservation of coniferous species. Future research focused on below ground processes, including soil characteristics, microbial growth and composition, should be designed to increase the overall understanding of gap dynamics and their impact on the whole forest.

\section{References}

Albanesi E, Gugliotta OI, Mercurio R (2005). Effects of gap size and within-gap position on seedlings establishment in silver fir stands. iForest 1 (1): 55-59. - doi: 10.3832/iforo448-0010055 Barik SK, Pandey HN, Tripathi RS, Rao P (1992). Microenvironmental variability and species-di- versity in treefall gaps in a subtropical broadleaved forest. Vegetatio 103: 31-40. [online] URL: http://link.springer.com/article/10.1007/BF 00033414

Bianchi L, Bottacci A, Calamini G, Maltoni A, Mariotti B, Quilghini G, Salbitano F, Tani A, Zoccola A, Paci M (2011). Structure and dynamics of a beech forest in a fully protected area in the northern Apennines (Sasso Fratino, Italy). iForest 4: 136-144. - doi: 10.3832/iforo564-004

Bottalico F, Travaglini D, Fiorentini S, Lisa C, Nocentini S (2014). Stand dynamics and natural regeneration in silver fir (Abies alba Mill.) plantations after traditional rotation age. iForest 7 : 313-323. - doi: 10.3832/iforog85-007

Boyden S, Binkley D, Shepperd W (2005). Spatial and temporal patterns in structure, regeneration, and mortality of an old-growth ponderosa pine forest in the Colorado Front Range. Forest Ecology and Management 219: 43-55. - doi: 10.1016/j.foreco.2005.08.041

Bradshaw FJ (1992). Quantifying edge effect and patch size for multiple-use silviculture: a discussion paper. Forest Ecology and Management 48: 249-264. - doi: 10.1016/0378-1127(92)90148-3 Brokaw NVL (1985). Treefalls, regrowth and community structure in tropical forests. In: "The Ecology of Natural Disturbance and Patch Dynamics" (Pickett SA, White DC eds). Academic Press, Inc, Orlando, USA, pp. 53-69.

Burton PJ, Macdonald SE (2011). The restorative imperative: challenges, objectives and approaches to restoring naturalness in forests. Silva Fennica 45: 843-863. - doi: 10.14214/sf.74

Caplat P, Anand M, Bauch C (2008). Interactions between climate change, competition, dispersal, and disturbances in a tree migration model. Theoretical Ecology 1: 209-220. - doi: 10.1007/s1 2080-008-0021-5

Chumanová-Vávrová E, Cudlín O, Cudlín P (2015). Spatial and temporal patterns of ground vegetation dominants in mountain spruce forests damaged by sulphur air pollution (Giant mountains, (zech Republic). Boreal Environment Research 20: 620-636. [online] URL: http://www. borenv.net/BER/pdfs/ber2o/ber20-620.pdf

Ciancio O, lovino F, Menguzzato G, Nicolaci A, Nocentini S (2006). Structure and growth of a small group selection forest of Calabrian pine in Southern Italy: a hypothesis for continuous cover forestry based on traditional silviculture. Forest Ecology and Management 224: 229-234. doi: 10.1016/j.foreco.2005.12.057

Coates KD, Burton PJ (1997). A gap-based approach for development of silvicultural systems to address ecosystem management ob- jectives. Forest Ecology and Management 99: 337-354. - doi: 10.1016/S0378-1127(97)00113-8 Cutini A, Gamba C, Mercurio R, Modica G, Piovanelli C, Simoncini S (2004). Osservazioni ecologiche su tagli a buche nelle abetine del Parco Nazionale delle Foreste Casentinesi [Ecological observations on small patch cuts in silver fir monocultures in the Casentino Forests National Park (Italy)]. Annali Istituto Sperimentale per la Selvicoltura 31: 27-38. [in Italian]

Dahir SE, Lorimer CG (1996). Variation in canopy gap formation among developmental stages of northern hardwood stands. Canadian Journal of Forest Research 26: 1875-92. - doi: 10.1139/x2 6-212

Daniel TW, Helms JA, Baker FS (1979). Principles of silviculture. McGraw-Hill, New York, USA pp. 452. [online] URL: http://www.cabdirect.org/ cabdirect/abstract/19790653044

Denslow JS (1980). Gap partitioning among tropical rainforest trees. Biotropica 12: 47-55. - doi: $10.2307 / 2388156$

Fang J, Lechowicz MJ (2006). Climatic limits for the present distribution of beech (Fagus L.) species in the world. Journal of Biogeography 33: 1804-1819. - doi: 10.1111/j.1365-2699.2006.015 33. $x$

Fernández-Ondoño $E$, Serrano LR, Jiménez $M N$, Navarro FB, Díez M, Martín F, Fernández J, Martinez FJ, Roca A, Aguilar J (2010). Afforestation improves soil fertility in south-eastern Spain. European Journal of Forest Research 129: 707717. - doi: 10.1007/s10342-010-0376-1

Gagnon JL, Jokela EJ, Moser WK, Huber DA (2004). Characteristics of gaps and natural regeneration in mature longleaf pine flatwoods ecosystems. Forest Ecology and Management 187: 373-80. - doi: 10.1016/j.foreco.2003.07.002 Giacobbe A (1958). Prospettive colturali delle foreste appenniniche [Cultural perspectives of the Apennine forests]. Annali Accademia Italiana di Scienze Forestali 7: 241-258. [in Italian] Gugliotta OI, Mercurio R (2003). Prime osservazioni su tagli a buche in pinete di pino nero in Abruzzo [Early observations on patch cuts in black pine forest in Abruzzo]. Monti e Boschi 54: 18-21. [in Italian]

Gugliotta OI, Mercurio R, Albanesi E (2006). Dynamics of natural regeneration in Pinus laricio stands from southern Apennines (Italy). Forest@ 3: 380-386. [in Italian with English summary]-doi: 10.3832/eforo401-0030380 Hamer KC, Hill JK, Benedick S, Mustaffa N, Sherratt TN, Chey VK, Maryati M (2003). Ecology of butterflies in natural and selectively logged forests of northern Borneo: the importance of 
habitat heterogeneity. Journal of Applied Ecology 40: 150-162. - doi: 10.1046/j.1365-2664.2003. 00783.x

Kneeshaw DD, Bergeron Y (1998). Canopy gap characteristics and tree replacement in the southeastern boreal forest. Ecology 79: 783794. - doi: 10.1890/0012-9658(1998)079[0783: CGCATR]2.0.CO;2

Lertzman KP (1992). Patterns of gap-phase replacement in a subalpine old-growth forest. Ecology 73: 657-669. - doi: 10.2307/1940772

Lindner M, Maroschek M, Netherer S, Kremer A, Barbati A, Garcia-Gonzalo J, Seidl R, Delzon S, Corona P, Kolström M, Lexer MJ, Marchetti M (2010). Climate change impacts, adaptive capacity, and vulnerability of European forest ecosystems. Forest Ecology and Management 259: 698-709. - doi: 10.1016/j.foreco.2009.09. 023

Madsen P (1995). Effects of soil water content, fertilization, light, weed competition and seedbed type on natural regeneration of beech (Fagus sylvatica). Forest Ecology and Management 72: 251-264. - doi: 10.1016/0378-1127(95) 97453-Y

Madsen P, Hahn K (2008). Natural regeneration in a beech-dominated forest managed by closeto-nature principles - a gap cutting based experiment. Canadian Journal of Forest Research 38: 1716-1729. - doi: 10.1139/Xo8-026

MAF/ISAFA (1988). Inventario Forestale Nazionale. Sintesi metodologica e risultati. [Italian National Forest Inventory. Methods and results]. Ministero dell'Agricoltura e delle Foreste. Istituto Sperimentale per l'Assestamento Forestale e per l'Alpicoltura, Trento, Italy, pp. 462. [in Italian]

Mercurio R (2000). Esperienze e prospettive sull'applicazione del taglio a buche nelle abetine del Parco Nazionale delle Foreste Casentinesi [Experiences and perspectives on the application of small patch cuts treatment in silver fir stands in the Casentino Forests National Park (Italy)]. L'Italia Forestale e Montana 55: 219-230. [in Italian]

Mercurio R, Spampinato G (2001). Dinamiche della vegetazione in tagli a buche nelle abetine del Parco Nazionale delle Foreste Casentinesi. [Vegetation dynamics in patch cuts in silver fir stands in the Casentino Forests National Park (Italy)]. Informatore Botanico Italiano 33: 215218. [in Italian]

Mercurio R, Mallamaci C, Muscolo A, Sidari M (2009). Gap size effects on tree regeneration in afforestations of Black pine (Pinus nigra Arn.). Forest@ 6: 312-319. [in Italian with English summary] - doi: 10.3832/eforo591-006

Muscolo A, Sidari M, Mercurio R (2007a). Variations in soil chemical properties and microbial biomass in artificial gaps in silver fir stands. European Journal of Forest Research 126: 5965. - doi: 10.1007/s10342-006-0145-3

Muscolo A, Sidari M, Mercurio R (2007b). Influence of gap size on organic matter decomposition, microbial biomass and nutrient cycle in
Calabrian pine (Pinus laricio Poiret) stands. Forest Ecology and Management 242: 412-418. doi: 10.1016/j.foreco.2007.01.058

Muscolo A, Sidari M, Bagnato S, Mallamaci C, Mercurio R (2010). Gap size effects on aboveand below-ground processes in a silver fir stand. European Journal of Forest Research 129: 355-365. - doi: 10.1007/s10342-009-0341-z

Muscolo A, Mallamaci C, Sidari M, Mercurio R (2011). Effects of gap size and soil chemical properties on the natural regeneration in black pine (Pinus nigra Arn.) stands. Tree and Forestry Science and Biotechnology 5: 65-71. [online] URL: http://www.academia.edu/download 145298778/TFSB_5Sl165-710.pdf

Nyland RD (2002). Silviculture. Concepts and applications. McGraw Hill, Boston, USA, pp. 682.

Rebertus AJ, Veblen TT (1993). Structure and tree-fall gap dynamics of old-growth Nothofagus forests in Tierra del Fuego, Argentina. Journal of Vegetation Science 4: 641-654. - doi: 10.2307/3236129

Ren JY, Kadir A, Yue M (2015). The role of treefall gaps in the natural regeneration of birch forests in the Taibai Mountains. Applied Vegetation Science 18: 64-74. - doi: 10.1111/avsc.12090 Rey F, Berger F (2006). Management of Austrian black pine on marly lands for sustainable protection against erosion (Southern Alps, France). New Forests 31: 535-543. - doi: 10.1007/s11 056-005-2741-3

Runkle JR (1982). Patterns of disturbance in some old-growth mesic forests of Eastern North-America. Ecology 63: 1533-1546. - doi: $10.2307 / 1938878$

Runkle JR (2000). Canopy tree turnover in oldgrowth mesic forests of eastern North America. Ecology 8: 554-567. - doi: 10.1890/00129658(2000)081[0554:CTTIOG]2.0.CO;2

Sapkota IP, Tigabu M, Odenm PC (2009). Species diversity and regeneration of old-growth seasonally dry Shorea robusta forests following gap formation. Journal of Forest Research 20: 7-14. - doi: 10.1007/s11676-009-0002-6

Scarascia-Mugnozza G, Oswald H, Piussi P, Radoglou K (2000). Forests of the Mediterranean region: gaps in knowledge and research needs. Forest Ecology and Management 132: 97-109. doi: 10.1016/S0378-1127(00)00383-2

Schliemann SA, Bockheim JG (2011). Methods for studying treefall gaps: a review. Forest Ecology and Management 261: 1143-1151. - doi: 10.1016/j. foreco.2011.01.011

Schnitzer SA, Carson WP (2001). Treefall gaps and the maintenance of species diversity in a tropical forest. Ecology 82: 913-919. - doi: 10.189 o/0012-9658(2001)082[0913:TGATMO]2.0.CO;2

Schnitzer SA, Mascaro J, Carson VP (2008). Treefall gaps and the maintenance of plant species diversity in tropical forests. In: "Tropical Forest Community Ecology" (Carson VP, Schnitzer SA eds). Blackwell Publishing, Oxford, UK, pp. 196-209. [online] URL: http:// wolfweb.unr.edu/ /dyer/classes/396/schnitzer. pdf
Seymour RS, White AS, De Maynadier PG (2002). Natural disturbance regimes in northeastern North America - evaluating silvicultural systems using natural scales and frequencies. Forest Ecology and Management 155: 357-367. - doi: 10.1016/S0378-1127(01)00572-2

Smith DM, Larson BC, Kelty MJ, Ashton PMS (1997). The practice of silviculture: applied forest ecology. John Wiley and Sons, New York, USA, pp. 537. [online] URL: http://www.cab direct.org/cabdirect/abstract/19980608088

Spies TA, Franklin JF, Klopsch M (1990). Canopy gaps in Douglas-fir forests of the Cascade Mountains. Canadian Journal of Forest Research 20: 649-658. - doi: 10.1139/x90-087

Stewart GH, Rose AB, Veblen TT (1991). Forest development in canopy gaps in old-growth beech (Nothofagus) forests. New Zealand Journal of Vegetation Science 2: 679-690. - doi: $10.2307 / 3236178$

Tíscar PA, Linares JC (2011). Pinus nigra subsp. salzmannii forests from Southeast Spain: using structure and process information to guide management. In: "Pine Forests: Types, Threats and Management" (Frisiras CT ed). Nova Science Publishers Inc., New York, USA, pp. 279314. [online] URL: http://crisantemo.upo.es/ export/portal/com/bin/portal/upo/profesores/jc lincal/books/1320340459911/

Van der Meer PJ, Dignan P, Savenh AG (1999). Effect of gap size on seedling establishment, growth and survival at three years in mountain ash (Eucalyptus regnans F. Muell.) forest in Victoria, Australia. Forest Ecology and Management 117: 33-42. - doi: 10.1016/So378-1127(98) 00471-X

Vrška T, Hort L, Adam D, Odehnalová P, Král K, Horal D (2006). Dynamika vývoje pralesovitých rezervací v CR II - Lužní lesy (Cahnov-Soutok, Ranšpurk, Jirina) [Developmental dynamics of virgin forest reserves in the Czech Republic II The lowland floodplain forests]. Academia, Praha, Czech Republic, pp. 216.

Xi W, Peet RK, Urban DL (2008). Changes in forest structure, species diversity and spatial pattern following hurricane disturbance in a Piedmont North Carolina forest, USA. Journal of Plant Ecology 1: 43-57. - doi: 10.1093/jpe/rtmo03 Yamamoto S (1994). Gap regeneration in primary evergreen broadleaved forests with or without a major canopy tree, Distylium racemosum, southwestern Japan: a comparative analysis. Ecological Research 9: 295-302. - doi: 10.1007/BF 02348415

Yamamoto S (1995). Gap characteristics and gap regeneration in subalpine old-growth coniferous forest, central Japan. Ecological Research 10: 31-39. - doi: 10.1007/BF02347653

York RA, Battles JJ, Heald RC (2003). Edge effects in mixed conifer group selection openings: tree height response to resource gradients. Forest Ecology and Management 179: 107121. - doi: 10.1016/S0378-1127(02)00487-5 